\section{Do the Benefits of Electronic Cigarettes Outweigh the Risks?}

\section{THE "PRO" SIDE}

Smoking is a dangerous lifestyle choice that results in increased risk of premature death or serious morbidities, such as cancer and coronary heart disease for the smoker and adverse health outcomes for the unborn children of pregnant women who smoke. ${ }^{1}$ Passive smoking also has serious health implications for both children and adults. The corollary of this situation is that smoking cessation is one of the most important, effective, and efficient health care interventions that can be undertaken. Within a year of quitting smoking, a former smoker's chance of developing heart disease drops to half that of a continuing smoker. ${ }^{2}$ Between 5 and 15 years after quitting, the chance of lung cancer decreases by almost half, and the risk of dying from cancer becomes similar to that of a nonsmoker. ${ }^{3}$ However, smoking is a particularly addictive behaviour, and stopping is not easy. While it is possible to stop smoking with just a behavioural intervention, the introduction of complementary pharmacological treatments, such as nicotine replacement therapy and varenicline, has increased rates of smoking cessation. The pharmacy profession has played its part by providing behavioural support and supplying therapies. Societal recognition of the dangers of smoking and support for a smoke-free environment have also contributed to the overall reduction of smoking prevalence in the Western world. For example, in Canada the prevalence of smoking has declined from about 26\% in 2001 to $20 \%$ in $2011^{4}$ and to $13 \%$ in $2015 .^{5}$

Despite these developments, quitting is still not possible for many current smokers, and alternative approaches are required. The introduction of e-cigarettes is one such alternative approach. The e-cigarette was first developed by a pharmacist in China in the early 2000s. It is a device that produces a nicotine aerosol by using a battery to heat a solution (typically based on propylene glycol or glycerol) of nicotine and flavouring agents. The device is cylindrical and has a mouthpiece for inhaling the vapour. In contrast to other forms of nicotine replacement, e-cigarettes allow the user to mimic the hand-to-mouth ritual of smoking a cigarette but deliver the vapourized nicotine to the lungs without the toxic by-products that accompany the smoking of tobacco. Thus, they intuitively feel more natural and acceptable to the habituated smoker.

A recent Cochrane review of the evidence for the effectiveness of e-cigarettes ${ }^{6}$ has suggested that e-cigarettes may increase the chance of a long-term quit. The review included 24 completed studies: 21 cohort studies; 2 RCTs comparing e-cigarettes with placebo e-cigarettes (i.e., without nicotine), with a combined sample of 662 participants, in which the 6-month quit rates were $9 \%$ with e-cigarettes and 5\% with the placebo device; and a third RCT, which compared e-cigarettes with a nicotine patch and found no difference in quit rates at 6 months. None of the included studies reported serious adverse effects from e-cigarettes, although it was acknowledged that the quality of the evidence was weak because of the small number of trials, the low event rates, and the wide confidence intervals around the estimates; furthermore, there is limited evidence of the long-term safety of e-cigarettes for either the user or those exposed passively to the vapours. ${ }^{7}$ Concerns have been expressed repeatedly that e-cigarettes represent a gateway to smoking cigarettes for young people, that they have toxic effects, and that they produce carcinogens. It is unclear the extent to which e-cigarettes are being used as aids to smoking cessation, for smoking reduction, or just as a new nicotine-related habit. It is generally acknowledged that all of this deserves thorough exploration.

Internationally, there is great variation in the extent to which countries support or restrict the use of e-cigarettes. A survey of different countries' regulatory approaches reported that 26 countries have banned all use of e-cigarettes and 21 have imposed restrictions on their sale. ${ }^{8}$ In Canada, e-cigarettes containing nicotine cannot be legally manufactured, sold, or imported, yet despite these prohibitions, the devices are available online and in some retail outlets. In the United States, an increasing number of states are banning indoor use of e-cigarettes. ${ }^{9}$ Among countries of the Western world, England has adopted a more liberal approach to e-cigarettes, prioritizing the importance of helping people to quit smoking over any safety concerns. Public Health England has claimed that e-cigarettes are $95 \%$ safer than smoked tobacco and has expressed concern that increasing numbers of people think e-cigarettes are more harmful than smoking. ${ }^{10}$ In a recent commissioned report, the same agency presented data confirming that the vast majority of e-cigarette users are current or ex-smokers and that the number of people using e-cigarettes who have never smoked is very small. ${ }^{11}$ The report also suggested that nicotine release into the environment is negligible and that there is no indication that e-cigarette users are exposed to dangerous levels of toxic chemicals, such as aldehydes. A recently published crosssectional survey involving 5863 adults who smoked concluded 
that continued abstinence was more likely for those using e-cigarettes than for those who bought over-the-counter nicotine replacement therapy. ${ }^{12}$ In a later analysis, the same authors estimated that in 2015 e-cigarettes helped about 18000 people to give up smoking in England, and suggested that these data justify use of these devices. ${ }^{13}$ There are also indications that the UK National Institute for Health and Care Excellence will soon endorse use of e-cigarettes as a smoking cessation aid.

No medicine is completely safe, and the decision on whether or not to use a medicine must balance the risks and the benefits. Although e-cigarettes are not classified as a medicine, similar principles should arguably be adopted when deciding on whether to support their use. This is the basis upon which Public Health England strongly supports the use of e-cigarettes, justifying this stance by highlighting the known negative health implications of smoked tobacco relative to the lesser risks of e-cigarettes. At present, e-cigarettes are largely unregulated, and there is little quality control over different components of e-cigarettes (the solvent, the additives such as flavour enhancers, or even the concentration of active ingredient). This lack of quality control is a valid cause for concern that needs to be addressed if e-cigarettes are to become an established part of the health care professional's armamentarium. However, recent European guidance, effective from 2017, has introduced rules to ensure minimum safety standards for the safety and quality of e-cigarettes, ${ }^{14}$ thus removing some of the potential for harm. Guidance on the product information leaflet and restrictions on advertising are also included in the European document. Supporting the wider adoption of such standards and recommending only licensed products for smoking cessation should allow patients to experience the benefits of e-cigarettes while minimizing the risks.

In summary, a quality-controlled e-cigarette, used as part of a structured smoking cessation program, could provide an effective additional option for smokers for whom other approaches have failed.

\section{References}

1. Schane RE, Ling PM, Glantz SA. Health effects of light and intermittent smoking: a review. Circulation. 2010;121(13):1512-22.

2. Ghadirian P. Sleeping with a killer: the effect of smoking on human health. Ottawa (ON): Health Canada; 2004.

3. The health benefits of smoking cessation: a report of the Surgeon General. Rockville (MD): US Department of Health and Human Services; 1990.

4. Janz T. Health at a glance. Current smoking trends. Ottawa (ON): Statistics Canada; 2015 [cited 2017 Nov 29]. Catalogue no. 82-624-X. Available from: https://www.statcan.gc.ca/pub/82-624-x/2012001/article/11676-eng.htm

5. Reid JL, Hammond D, Rynard VL, Madill CL, Burkhalter R. Tobacco use in Canada: adult tobacco use. Waterloo (ON): University of Waterloo, Propel Centre for Population Health Impact; 2017 [cited 2017 Nov 29]. Available from: https:/uwaterloo.ca/tobacco-use-canada/adult-tobacco-use

6. Hartmann-Boyce J, McRobbie H, Bullen C, Begh R, Stead LF, Hajek P. Electronic cigarettes for smoking cessation. Cochrane Database Syst Rev. 2016;9:CD010216.

7. Jensen RP, Luo W, Pankow JF, Strongin RM, Peyton DH. Hidden formaldehyde in e-cigarette aerosols [letter]. NEngl J Med. 2015;372(4):392-4.

8. Country laws regulating e-cigarettes: a policy scan. Baltimore (MD): Johns Hopkins Bloomberg School of Public Health, Institute for Global Tobacco
Control; 2017 [cited 2017 Nov 29]. Available from: http://globaltobacco control.org/e-cigarette/country-laws-regulating-e-cigarettes

9. Glenza J. E-cigarette bans highlight public health divide between US and UK researchers. The Guardian. 2017 Oct 24 [cited 2017 Nov 30]. Available from: https:/www.theguardian.com/society/2017/oct/24/e-cigarette-banshighlight-public-health-divide-between-us-and-uk-researchers

10. McNeill A, Hajek P. Underpinning evidence for the estimate that e-cigarette use is around 95\% safer than smoking: authors' note. London (UK): Public Health England; 2015 [cited 2017 Nov 29]. Available from: https://www.gov.uk/government/publications/e-cigarettes-an-evidenceupdate

11. McNeill A, Brose LS, Calder R, Hitchman SC, Hajek P, McRobbie H. Ecigarettes: an evidence update. A report commissioned by Public Health England. London (UK): Public Health England; 2015 [cited 2017 Nov 29]. Available from: https://www.gov.uk/government/uploads/system/uploads/attachment_ data/file/457102/Ecigarettes_an_evidence_update_A_report_ commissioned_by_Public_Health_England_FINAL.pdf

12. Brown J, Beard E, Kotz D, Michie S, West R. Real-world effectiveness of e-cigarettes when used to aid smoking cessation: a cross-sectional population study. Addiction. 2014;109(9):1531-40.

13. Beard E, West R, Michie S, Brown J. Association between electronic cigarette use and changes in quit attempts, success of quit attempts, use of smoking cessation pharmacotherapy, and use of stop smoking services in England: time series analysis of population trends. BMJ. 2016;354:i4645.

14. Directive 2014/40/EU of the European Parliament and of the Council of 3 April 2014 on the approximation of the laws, regulations and administrative provisions of the Member States concerning the manufacture, presentation and sale of tobacco and related products and repealing Directive 2001/37/EC. Off J Eur Union. 2014 [cited 2017 Nov 29];57(L127):1-38. Available from: https://ec.europa.eu/health//sites/health/files/tobacco/docs/ dir_201440_en.pdf.

Christine M Bond, BPharm, PhD, MEd

Emeritus Professor

Centre of Academic Primary Care, University of Aberdeen

Foresterhill, Aberdeen, Scotland

Christine Bond is also an Associate Editor with the Canadian Journal of Hospital Pharmacy.

Competing interests: None declared.

\section{THE "CON" SIDE}

The 21st century has given rise to a novel method of commercializing public nicotine dependence, in the form of electronic nicotine delivery systems (ENDS), such as electronic cigarettes (e-cigarettes). Smoking combustible tobacco is now passé, and "vaping", as it is termed, has become the latest popular trend among the fashionable, including A-listers such as Leonardo DiCaprio and Katy Perry. If history has taught us anything, it is not to rely on celebrities for sound health advice. The vapour trail is nothing more than a smokescreen.

E-cigarettes use a battery to heat a solution that is vapourized and inhaled. ${ }^{1}$ This "e-liquid" typically comprises propylene glycol (i.e., antifreeze) and/or glycerol, nicotine, and flavours (e.g., tobacco, menthol, fruit, candy). ${ }^{2}$ To be blunt, using an e-cigarette is not unlike inhaling vapourized, berry-flavoured aircraft de-icing fluid. As of this 
writing (in late 2017), Health Canada does not permit or regulate the sale of ENDS. In other words, none of the currently available forms of nicotine-containing e-cigarettes are legal in Canada, and this lack of oversight means that an e-liquid could contain pretty much anything. Furthermore, e-liquids are available in various strengths of nicotine, ranging from 6 to $36 \mathrm{mg} / \mathrm{mL}$, ${ }^{3}$ which could result in toxic effects if the specified concentration is misinterpreted or the amount is incorrectly measured. Additionally, some bottles of flavoured e-liquid are adorned with brightly coloured pictures of fruit, which means they could be mistaken for juice or candy. Accidental ingestion of e-liquid by children is particularly concerning - a nicotine dose of about $1 \mathrm{mg} / \mathrm{kg}$ could be lethal, and this amount could be delivered in a few drops of a concentrated solution. ${ }^{4}$

No data are available regarding the long-term safety of ENDS, but there is rapidly evolving evidence that links vaping with pulmonary toxicity. ${ }^{5}$ Use of an ENDS has been associated with respiratory symptoms (e.g., wheezing, coughing), increased airway hypersensitivity, increased airway resistance, decreased host immunity, and increased alveolar cytotoxicity.,6 Furthermore, ENDS may produce a variety of carcinogenic compounds, such as formaldehyde, acetaldehyde, and acrolein. ${ }^{7,8}$ Exposure to diacetyl, a common e-cigarette flavouring with a buttery or creamy taste, has been associated with acute-onset bronchiolitis obliterans or "popcorn lung", a severe and irreversible obstructive pulmonary condition. ${ }^{9}$ A new study estimated that a frequent user of an e-cigarette (defined by the authors as $\geq 250$ puffs/day) would be exposed to levels of formaldehyde, acrolein, and diacetyl that exceed occupational limits in the United States. ${ }^{7}$ As well, ENDS may produce heavy metals, such as chromium, lead, and nickel. ${ }^{10}$ Nicotine itself is not without risk: a retrospective cohort study conducted in Sweden showed that individuals who continued to use smokeless tobacco after myocardial infarction, as opposed to those who quit smoking, had an approximately 2 -fold higher mortality rate over 2 years. ${ }^{11}$ Finally, the safety of exposure to the ostentatious plume of vapour created by an e-cigarette user ("second-hand vape") is completely unknown.

Other hazards are becoming known. Traditional cigarettes may burn your fingers, but ENDS may explode. This rare but serious occurrence, caused by overheating of the battery, should give pause to even the most fervent e-cigarette advocate. A series of images of ENDS explosion injuries was recently published; these included flame and chemical burns, tooth loss, and extensive soft-tissue damage. ${ }^{12}$ Dramatic visuals can be useful prompts; for example, images of diseased lungs on cigarette packages may motivate some individuals to quit smoking. Perhaps ENDS packages should feature pictures of explosion injuries.

I concede that, at present, ENDS appear to be safer than traditional cigarettes, and they may have a role in harm reduction. ${ }^{2}$ However, cessation of both smoking and vaping is preferred. Evidence for using e-cigarettes for smoking cessation, though promising, is not sufficiently robust to recommend them for this indication, ${ }^{13}$ a position that is supported by a policy statement from the American Heart Association. $^{3}$
The ENDS industry has employed aggressive marketing to normalize vaping and subvert the social stigma associated with smoking. ${ }^{14}$ Such marketing is particularly concerning when directed toward adolescents, especially those who would not have otherwise tried smoking but who may start using e-cigarettes as a result. A report from the US Centers for Disease Control and Prevention (CDC) estimated that approximately $70 \%$ of middle and high school students were exposed to ENDS advertisements in 2014. ${ }^{15}$ E-cigarettes are perceived as safer than traditional cigarettes (particularly among youth) and are portrayed as more socially acceptable in popular culture. Advertisements depict e-cigarettes as sexy, rebellious, independent, and trendy-I would even venture to say that if the film Rebel Without a Cause were remade today, the poster would feature James Dean's character with an e-cigarette. ENDS may also be more accessible for young people and easier to hide from authority figures.

To be pragmatic, e-liquid flavouring is an unequivocally blatant strategy to target youth. Candy flavours, such as cotton candy, gummy bears, Skittles, and Froot Loops (all of which exist), are created largely to appeal to young people. ${ }^{16}$ A survey of US adolescents aged 13-17 years found that they were more likely to try an e-cigarette offered by a friend if it were fruit-flavoured than if it were tobacco-flavoured. ${ }^{17}$ As well, respondents believed that fruit-flavoured e-cigarettes were less harmful than those flavoured like tobacco, and about one-fifth stated that they believed e-cigarettes did not contain nicotine or they were uncertain about nicotine content. A CDC report using data from the 2016 National Youth Tobacco Survey showed that e-cigarettes were the most commonly used tobacco product among teenaged students- $-4.3 \%$ and $11.3 \%$ of middle and high school students, respectively, had used an e-cigarette within the past 30 days. ${ }^{18}$ There is also evidence that ENDS may be a gateway to smoking traditional cigarettes. $^{19,20}$ A recent meta-analysis demonstrated that ever e-cigarette users had 3.6-fold greater adjusted odds of becoming a smoker relative to never-users. ${ }^{20}$

E-cigarettes may prove useful as a harm reduction strategy, but they are far from safe, and at this point the overall potential benefits do not outweigh the risks. This conclusion is affirmed by emerging evidence of ENDS-associated pulmonary toxicity and exposure to carcinogens, and the lack of long-term data. Oh, and they may explode. Meanwhile, industry is unabashedly recruiting a whole new generation of nicotine-addicted youth with little to no regulatory oversight. They say hindsight is 20/20, which is of particular relevance in medicine. Seventy years ago, tobacco cigarettes were not only considered safe, but were also purported to have positive health effects, and we all know how that turned out.

\section{References}

1. Dinakar C, O'Connor GT. The health effects of electronic cigarettes. NEngl J Med. 2016;375(14):1372-81.

2. Hajek P, Etter JF, Benowitz N, Eissenberg T, McRobbie H. Electronic cigarettes: review of use, content, safety, effects on smokers and potential for harm and benefit. Addiction. 2014;109(11):1801-10.

3. Bhatnagar A, Whitsel LP, Ribisl KM, Bullen C, Chaloupka F, Piano MR, et al. Electronic cigarettes: a policy statement from the American Heart Association. Circulation. 2014;130(16):1418-36. 
4. Gupta S, Gandhi A, Manikonda R. Accidental nicotine liquid ingestion: emerging paediatric problem. Arch Dis Child. 2014;99(12):1149.

5. Chun LF, Moazed F, Calfee CS, Matthay MA, Gotts JE. Pulmonary toxicity of e-cigarettes. Am J Physiol Lung Cell Mol Physiol. 2017;313(2):L193-L206.

6. Wang MP, Ho SY, Leung LT, Lam TH. Electronic cigarette use and respiratory symptoms in Chinese adolescents in Hong Kong. JAMA Pediatr. 2016;170(1):89-91.

7. Logue JM, Sleiman M, Montesinos VN, Russell ML, Litter MI, Benowitz NL, et al. Emissions from electronic cigarettes: assessing vapers' intake of toxic compounds, secondhand exposures, and the associated health impacts. Environ Sci Technol. 2017;51(16):9271-9.

8. Jensen RP, Luo W, Pankow JF, Strongin RM, Peyton DH. Hidden formaldehyde in e-cigarette aerosols [letter]. N Engl J Med. 2015;372(4):392-4.

9. Barrington-Trimis JL, Samet JM, McConnell R. Flavorings in electronic cigarettes: an unrecognized respiratory health hazard? JAMA. 2014;312(23): 2493-4.

10. Hess CA, Olmedo P, Navas-Acien A, Goessler W, Cohen JE, Rule AM. E-cigarettes as a source of toxic and potentially carcinogenic metals. Environ Res. 2017;152:221-5.

11. Arefalk G, Hambraeus K, Lind L, Michaëlsson K, Lindahl B, Sundström J. Discontinuation of smokeless tobacco and mortality risk after myocardial infarction. Circulation. 2014;130(4):325-32.

12. Brownson EG, Thompson CM, Goldsberry S, Chong HJ, Friedrich JB, Pham TN, et al. Explosion injuries from e-cigarettes [letter]. N Engl J Med. 2016;375(14):1400-2.

13. Hartmann-Boyce J, McRobbie H, Bullen C, Begh R, Stead LF, Hajek P. Electronic cigarettes for smoking cessation. Cochrane Database Syst Rev. 2016;9:CD010216.

14. Gostin LO, Glasner AY. E-cigarettes, vaping, and youth. JAMA. 2014; 312(6):595-6
15. E-cigarettes ads and youth. Atlanta (GA): Centers for Disease Control and Prevention; 2017 Mar [cited 30 Nov 2017]. Available from: https:// www.cdc.gov/vitalsigns/ecigarette-ads/index.html

16. Nine e-juice flavors that sound just like kids' favorite treats. Washington (DC): Campaign for Tobacco-Free Kids; 2014 Jun 11 [cited 30 Nov 2017]. Available from: https://www.tobaccofreekids.org/blog/2014_06_11_ecigarettes

17. Pepper JK, Ribisl KM, Brewer NT. Adolescents' interest in trying flavoured e-cigarettes. Tob Control. 2016;25(Suppl 2):ii62-ii66.

18. Jamal A, Gentzke A, Hu SS, Cullen KA, Apelberg BJ, Homa DM, et al. Tobacco use among middle and high school students - United States, 20112016. MMWR Morb Mortal Wkly Rep. 2017;66(23):597-603.

19. Leventhal AM, Strong DR, Kirkpatrick MG, Unger JB, Sussman S, Riggs $\mathrm{NR}$, et al. Association of electronic cigarette use with initiation of combustible tobacco product smoking in early adolescence. JAMA. 2015;314(7):700-7.

20. Soneji S, Barrington-Trimis JL, Wills TA, Leventhal AM, Unger JB, Gibson LA, et al. Association between initial use of e-cigarettes and subsequent cigarette smoking among adolescents and young adults: a systematic review and meta-analysis. JAMA Pediatr. 2017;171(8):788-97.

Arden R Barry, BSc, BSc(Pharm), PharmD, ACPR

Chilliwack General Hospital, Lower Mainland Pharmacy Services Chilliwack, British Columbia

Faculty of Pharmaceutical Sciences

University of British Columbia

Vancouver, British Columbia

Competing interests: None declared. 